\section{O PAPEL DO PROFESSOR DE EDUCAÇÃO FÍSICA NOS ANOS INICIAIS NAS ESCOLAS ESTADUAIS DE ENSINO INTEGRAL DO ESTADO DE SÃO PAULO}

\author{
THE ROLE OF PHYSICAL EDUCATION TEACHERS DURING THE EARLY \\ YEARS AT FULL-TIME STATE SCHOOLS IN SÃO PAULO
}

\author{
EL PAPEL DEL PROFESOR DE EDUCACIÓN FÍSICA EN LOS AÑOS INICIALES \\ EN LAS ESCUELAS PÚBLICAS DE ENSEÑANZA INTEGRAL DE SÃO PAULO
}

Cássia Maria Hess*, Marcos Neira**, Eliana Toledo*

\begin{abstract}
Palavras chave:
Ensino fundamental e médio.

Educação Física.

Professores

escolares.

Resumo: Esta pesquisa teve como objetivo identificar e problematizar o papel do professor de Educação Física dos anos iniciais do ensino fundamental, nas escolas de Ensino Integral do Estado de São Paulo. Trata-se de uma pesquisa documental, de abordagem qualitativa, com Análise Temática (BARDIN, 2011). Identificou-se que 0 professor de Educação Física possui, além de suas atribuições específicas, um papel mais interdisciplinar com o de Arte, com a responsabilidade ainda de acompanhar os alunos no horário de saída e de almoço, e de participar das assembleias e dos agrupamentos por dificuldades. Para complementar a carga horária, o professor de Educação Física deve atuar também como apoio docente. Concluiu-se que os documentos oficiais atribuem ao professor de Educação Física, além de suas atribuições legais, um papel de disciplinador, recreador e auxiliar, com multifunções, conforme a própria história da área identifica.
\end{abstract}

Keywords:

Education, primary and secondary. Physical Education. School teachers.

Palabras clave: Educación primaria y secundaria. Educación Física. Profesores.
Abstract: This study identifies and discusses the role of Physical Education teachers who work in the early years of elementary school at full time state schools in São Paulo. It is a qualitative documentary study including Thematic Analysis (BARDIN, 2011). The study found that Physical Education teachers, in addition to their specific duties, play a more interdisciplinary role regarding Art. They are also responsible for monitoring students at exit and lunch times and participating in assemblies and so-called 'difficulty groups'. To complement their workload, they also have to provide teaching assistance. The study finds that official documents determine that these professionals play a disciplinary, a recreational, and an assistant role with multiple functions according to the field's own history.

Resumen: Esta investigación tuvo como objetivo identificar y problematizar el papel del profesor de Educación Física de los años iniciales de la Enseñanza Primaria, en las escuelas públicas de Enseñanza Integral de São Paulo. Se trata de una investigación documental con enfoque cualitativo y Análisis Temático (BARDIN, 2011). Identificamos que el profesor de Educación Física tiene, además de sus atribuciones específicas, un papel más interdisciplinario con el de Arte, con la responsabilidad, además, de acompañar a los alumnos en el horario de la salida y en el almuerzo, y participar en las asambleas y las agrupaciones. Para complementar la carga horaria, el profesor de Educación Física debe actuar también como apoyo docente. Se concluye que los documentos oficiales atribuyen al profesor de Educación Física, además de sus atribuciones legales, un papel de controlador de la disciplina, de recreador y de auxiliar, con multifunciones, conforme la propia historia del área identifica.
*Unicamp. Campinas, SP, Brasil. E-mail: cassiahess@gmail.com; eliana.toledo@fca.unicamp.br

** Universidade de São Paulo. São Paulo, SP, Brasil. E-mail:mgneira@usp.br

Recebido em: 01/04/2018 Aprovado em: 23/10/2018

DOI: https://doi.org/10.22456/1982-8918.81617 (c) (i) () Licence 


\section{INTRODUÇÃO}

Em 2012, a Secretaria da Educação do Estado de São Paulo implantou o Programa de Ensino Integral em algumas escolas do ensino médio. No ano seguinte, ampliou 0 alcance do programa para as escolas dos anos finais do ensino fundamental e, finalmente, em 2014, foram contempladas as instituições destinadas aos anos iniciais do ensino fundamental.

Conforme as diretrizes do programa, "[...] não apenas o desenho curricular dessas escolas é diferenciado, mas também a sua metodologia, o modelo pedagógico e o modelo de gestão escolar, enquanto instrumento de planejamento, gerenciamento e avaliação das atividades de toda comunidade escolar" (SÃO PAULO, 2012, p. 12). Ainda segundo a visão oficial, "[...] a formação de indivíduos autônomos, solidários e competentes contemplará, nessa formação, conhecimentos, habilidades e valores direcionados ao pleno desenvolvimento da pessoa humana e a seu preparo para o exercício da cidadania" (SÃO PAULO, 2014c, online).

Com vistas a subsidiar as unidades escolares na implementação do programa, uma série de textos foram elaborados e disponibilizados no site institucional da Secretaria da Educação do Estado de São Paulo a fim de que pudessem ser acessados pelos profissionais da educação diretamente envolvidos, uma vez que se trata de uma política pública em franca expansão, e que, provavelmente, impactará na organização e no funcionamento das unidades escolares e na docência do professor de Educação Física, o qual já recebeu diversos papéis no decorrer dos tempos, entre eles de higienista, médico, militar etc.

Assim, o objetivo desta pesquisa foi identificar e problematizar o papel do professor de Educação Física dos anos iniciais do ensino fundamental, nas escolas de Ensino Integral do Estado de São Paulo.

\section{MÉTODO}

Trata-se de uma pesquisa documental, com abordagem qualitativa. Segundo Gil (2002, p. 45), a pesquisa documental, vale-se "[...] de materiais que não recebem ainda um tratamento analítico, ou que ainda podem ser reelaborados de acordo com os objetivos da pesquisa".

O corpus de análise constituiu-se dos textos oficiais publicados nos anos 2014 e 2015, elaborados por uma equipe específica da Secretaria da Educação do Estado de São Paulo', para orientar a implementação do modelo de Escola de Ensino Integral nos anos iniciais do ensino fundamental.

Utilizaram-se como fonte primária os seguintes documentos:

a) Guia de Organização Curricular dos Tempos e Espaços do Programa Ensino Integral nos anos iniciais do Ensino Fundamental da Secretaria de Estado da Educação de São Paulo. (Versão Preliminar) - dezembro de 2014 (SÃO PAULO, 2014a);

b) Modelo Pedagógico do Programa de Ensino Integral nos anos iniciais do Ensino Fundamental da Secretaria de Estado da Educação de São Paulo (SEE-SP) - agosto de 2014 (SÃO PAULO, 2014b);

c) Resolução SE-52, que dispõe sobre a organização e o funcionamento das escolas estaduais do Programa Ensino Integral (SÃO PAULO, 2014c);

1 Coordenadoria de Gestão da Educação Básica (CGEB); Departamento de Desenvolvimento Curricular e de Gestão da Educação Básica (DEGEB); Centro de Ensino Fundamental dos Anos Iniciais (CEFAI), sob a Direção de Sonia de Gouveia Jorge (Diretora do CEFAl) e demais participantes 
d) Resolução SE no 6, que altera dispositivos da Resolução SE 52, de 2-10-2014, que dispõe sobre a organização e o funcionamento das escolas estaduais do Programa Ensino Integral (SÃO PAULO, 2015).

Após de selecionados os documentos ao confronto coma teorização curricular destinados às escolas de ensino integral dos anos iniciais, destacamos as orientações destinadas ao componente Educação Física e à respectiva função do professor para, finalmente, realizar 0 tratamento dos resultados e interpretação.

Deste modo, para a análise dos documentos, realizou-se uma pré-análise, a exploração do material e, em seguida, o tratamento dos resultados e a interpretação, denominada de Análise Temática (BARDIN, 2011).

\section{ANÁLISE E DISCUSSÃO}

\subsection{A concepção de currículo e a organização curricular}

A princípio, etimologicamente, a palavra "currículo", do latim curriculum, significa "pista de corrida". Segundo Silva (2013), nos tornamos "o que somos" no decorrer dessa corrida, que nada mais é do que o currículo. Contudo, Lopes e Macedo (2011) defendem que não é tão simples responder "o que é currículo" e que, desde o início do século XX, os estudos apontam para diversas definições, que perpassam o que tem sido chamado de currículo no cotidiano escolar, e englobam desde os guias curriculares sobre o que ocorre em sala de aula, até a grade curricular composta por disciplinas ou atividades e cargas horárias, ementas e programas das disciplinas ou atividades, os planos de ensino dos professores, as experiências propostas e vivenciadas pelos alunos, evidenciando uma ideia de ordem de forma prévia ou não das situações de aprendizagem a serem realizadas pelos professores. Mesmo assim, Lopes e Macedo (2011) afirmam que existem ainda outras questões que vêm sendo colocadas em jogo como objeto de disputas na teoria curricular. Desse modo, pela discussão ser ampla, nesta pesquisa, como segue, nos atemos com afinco à concepção de currículo somente da Escola de Ensino Integral.

A concepção curricular que permeia o Programa Ensino Integral nos anos iniciais do ensino fundamental é de um "currículo integrado", que deve ser compreendido pelos docentes e por todos os envolvidos da unidade escolar fundamentalmente para a organização da rotina dos tempos e dos espaços nas ações pedagógicas, rompendo "[...] a barreira da fragmentação ao preocupar-se com o aumento das possibilidades para a integração pessoal e socioemocional, por meio da organização do currículo, em torno de problemas e de questões significativas, identificadas na comunidade escolar" (SÃO PAULO, 2014a, p. 5).

A preocupação com a formação integral é ressaltada nos documentos oficiais:

O Programa de Ensino Integral nos Anos Iniciais do Ensino Fundamental orientase por uma concepção democrática e emancipatória de educação. Assim, pretende contribuir para o desenvolvimento integral dos estudantes por meio de uma formação humanística e cultural que propicie aprendizagens para que estes possam atuar autonomamente na escola e na sociedade, orientados por valores como respeito, solidariedade, tolerância e perseverança (SÃO PAULO, 2014b, p.12). 
Os documentos mencionam que a proposta de educação integral do programa está em consonância com os pilares para a educação do século XXI,

[...] visando ao desenvolvimento físico, cognitivo, afetivo e social do educando.

[...] Pelas razões expostas, o Programa de Ensino Integral nos Anos Iniciais do Ensino Fundamental reconhece a necessidade de promover, intencional e sistematicamente, 0 desenvolvimento das habilidades socioemocionais, em estreita articulação com o desenvolvimento das habilidades cognitivas, por meio da educação emocional. Nesse processo, serão privilegiadas habilidades que se estruturam com base nos valores do respeito, da solidariedade, da tolerância e da perseverança (SÃO PAULO, 2014a, p.25).

Na Educação Física, a "formação integral" do ser humano, segundo Bracht et al. (2007) é algo que se naturalizou e se disseminou na área, sem mais questionamentos e explicações. Foi instituída "[...] como uma proposição vinculada a uma perspectiva pedagógica progressista e crítica. Sua intenção era, principalmente, fugir da dicotomia corpo e mente". "Na segunda metade da década de 80, a defesa de uma formação integral permaneceu presente em algumas obras, como em Freire (1989) e Tani et al. (1988)" [...] (BRACHT et al., 2007, p. 63).

\subsection{A Educação Física nas resoluções estaduais}

A Resolução SE-52 dispõe sobre a organização e o funcionamento das escolas estaduais do Programa Ensino Integral:

Artigo $5^{0}$ - A organização curricular, a ser adotada nas escolas do Programa Ensino Integral, sustentada pelos princípios integradores dos diferentes conhecimentos, de forma contextualizada e interdisciplinar, fundamentar-se-á:

I - nos anos iniciais do Ensino Fundamental: na cultura, na ciência e nas habilidades sócio-emocionais [sic], contemplando as diferentes linguagens artísticas, bem como a cultura do movimento, o multiletramento, a integração escola-comunidade e a tecnologia;

Parágrafo único - As matrizes curriculares, a que se refere o caput deste artigo, serão implantadas em todas as turmas do Ensino Fundamental e do Ensino Médio, compreendendo as disciplinas da Base Nacional Comum e da Parte Diversificada, incluídas as Atividades Complementares (SÃO PAULO, 2014C).

A Resolução considera que a Parte Diversificada (PD) deve enriquecer e complementar a Base Nacional Comum (BNC) ${ }^{2}$, pois se trata de um currículo integrado e não "[...] da somatória ou sobreposição de trabalhos diferentes, mas a síntese entre os dois blocos de Componentes Curriculares, que se transformam na Matriz da Escola de Ensino Integral" (SÃO PAULO, 2014a, p. 35). A proposta do programa visa à articulação da BNC e da PD, sustentada pelos seguintes eixos: o Protagonismo, a Educação Emocional e o Multiletramento, que devem ser utilizados como um norte em todas as disciplinas, uma vez que "[...] em alguma medida, todas as disciplinas orbitariam em torno dos eixos. A ideia do eixo integrador é fundamentada em categorias consolidadas na área educacional: interdisciplinaridade" (SÃO PAULO, 2014a, p. 35). O quadro a seguir apresenta a distribuição das atividades formativas do Ensino Integral nos anos iniciais do ensino fundamental.

2 É importante destacar que, naquele momento, inexistia o documento oficial Base Nacional Curricular Comum. No entanto, a noção de uma base nacional comum estabelecida na LDB no artigo $26^{\circ}$ definia que "os currículos da educação infantil, do ensino fundamental e do ensino médio devem ter base nacional comum, a ser complementada, em cada sistema de ensino e em cada estabelecimento escolar, por uma parte diversificada, exigida pelas características regionais e locais da sociedade, da cultura, da economia e dos educandos" (Redação dada pela LEI n 12.796, de 2013) (BRASIL, 2013). 
Quadro 1 - Matriz curricular do Ensino Fundamental (anos iniciais).

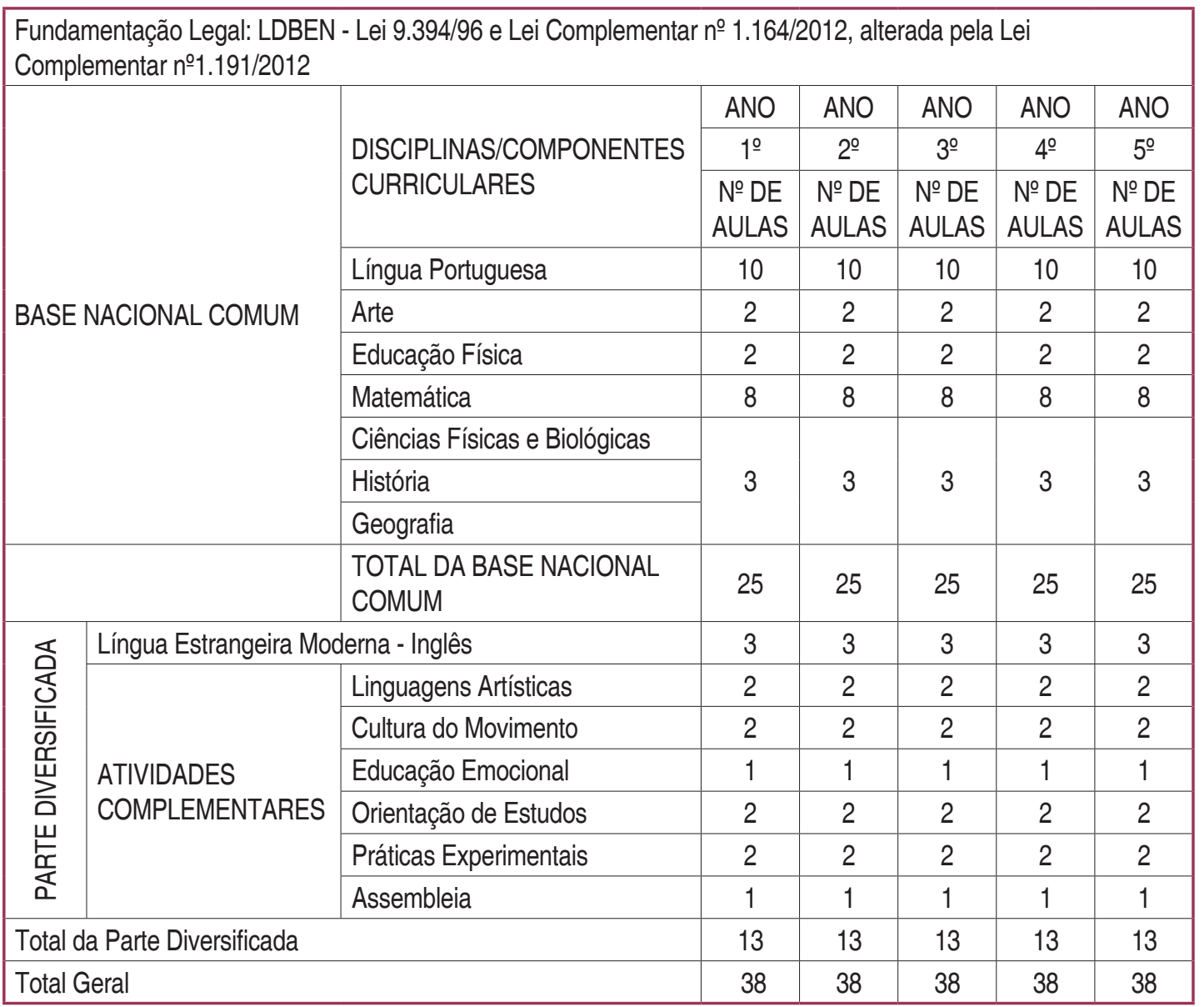

Fonte: Resolução SE-52, de 02/10/2014 (SÃO PAULO, 2014c)

Conforme se observa, o Programa de Ensino Integral da SEE-SP simplesmente acrescenta ao período de aulas "comum" (que contempla as disciplinas da BNC) as denominadas Atividades Complementares (AC), com as disciplinas de Inglês, Educação Emocional, Cultura do Movimento, Linguagens Artísticas, Assembleia, Orientação de Estudos e Práticas Experimentais.

Segundo Hess e Toledo (2016), alinhando-se ao que estabelece a LDB 9.394/1996, a Educação Física figura como componente curricular com duas aulas semanais, quantidade bem inferior àquela destinada à Língua Portuguesa e à Matemática, mas semelhante à carga horária de Arte e maior que o tempo letivo destinado às disciplinas Ciências Físicas e Biológicas, História e Geografia.

Dentre as atividades complementares que caracterizam a PD da Matriz Curricular proposta, chama atenção a presença da "Cultura do Movimento". Ao cartografarem o termo, Neira e Gramorelli (2017) identificaram diversos vetores de força que têm influenciado a concepção de cultura e, por conseguinte, as expressões "cultura corporal", "cultura do movimento" e "cultura corporal de movimento". Embora tenham se tornado hegemônicas nas discussões curriculares desde a década de 1990, as influências das teorias críticas, da Antropologia e dos estudos culturais impulsionaram o surgimento de significações distintas. Em alguns casos, o termo perdeu todo o potencial crítico inicial, passando a ser empregado, inclusive, nas propostas de cunho tecnicista. 
Na concepção de Soares et al. (1992), a Educação Física como disciplina escolar deve abordar de maneira pedagógica os temas da "cultura corporal", a saber: jogo, ginástica, esporte, dança, acrobacias e outros, sendo este o conhecimento que estabelece o conteúdo da área.

Nos Parâmetros Curriculares Nacionais (PCN) (BRASIL, 1997) do primeiro e segundo ciclos do ensino fundamental, a Educação Física é abordada como "cultura corporal", enquanto que o documento do terceiro e quarto ciclos do ensino fundamental (BRASIL, 1998) aponta a Educação Física como "cultura corporal de movimento". No ensino médio, o aluno deverá adquirir sólidos conhecimentos sobre a "cultura corporal" (BRASIL, 2000). Assim, percebese que, no mesmo conjunto documental (PCN), em suas diferentes partes ou fases (ciclos escolares), há denominações distintas para abordar a Educação Física. Além disso, Neira e Gramorelli (2017) constataram que esses documentos recorrem a referenciais da psicobiologia para justificar opções tão diferentes.

Já na Proposta Curricular do Estado de São Paulo de Educação Física, o termo utilizado é "Cultura de Movimento", entendido como um:

\begin{abstract}
[...] conjunto de significados/sentidos, símbolos e códigos que se produzem e reproduzem dinamicamente nos jogos, esportes, danças e atividades rítmicas, lutas, ginásticas etc., os quais influenciam, delimitam, dinamizam e/ou constrangem o Se Movimentar dos sujeitos, base de nosso diálogo expressivo com o mundo e com os outros (SÃO PAULO, 2010, p. 43).
\end{abstract}

Adotando a perspectiva pós-crítica, Neira (2018) compreende que a cultura corporal abarca a totalidade da produção discursiva e não discursiva a respeito das práticas corporais, entendidas como artefatos culturais e, portanto, passíveis de infinitas significações.

Gramorelli (2014) e Bracht (1999) apontam que todos os termos citados anteriormente e utilizados na área ("cultura corporal", "cultura de movimento", "cultura corporal de movimento") podem variar dependendo das concepções daqueles que os utilizam. Convergentemente com as ideias dos autores, defendemos que esses significados diversos podem gerar conflitos epistemológicos para a área, principalmente quando os termos não são bem definidos e significados.

A questão é que a expressão jamais havia sido utilizada para designar uma atividade tal como consta no documento legal analisado, sendo importante destacar que, em alguns trechos, a "cultura do movimento" é empregada como sinônimo de "cultura corporal":

No entanto, muitos já perceberam que, enquanto joga futebol, handebol, voleibol ou basquete, a criança expressa sentimentos, crenças e modos de pensar: um conjunto de elementos da cultura corporal, ou cultura do movimento. Essa mudança está em curso e leva o educador à compreensão da necessidade de ampliar os seus objetivos educativos com vista à formação de cidadãos (SÃO PAULO, 2014a, p. 85, grifo nosso).

Ora, não se trata de mera questão semântica. A teorização curricular da Educação Física oferece indícios o suficiente para compreendermos o termo como objeto de estudo do componente alinhado a uma certa epistemologia. Se a intenção foi diferenciar a PD das aulas de Educação Física da BNC da matriz curricular, é possível dizer que a escolha apenas ampliará a confusão. Além disso, o mesmo equívoco se estende à nomenclatura "linguagens artísticas": inúmeras propostas curriculares para o componente Arte reconhecem como objeto de estudo justamente as linguagens artísticas musical, visual, teatro e dança. 


\subsection{A (re)organização curricular e o papel do professor de Educação Física}

A respeito da distribuição de responsabilidades, os textos oficiais (SÃO PAULO, 2014a; 2014b) especificam que, para o componente Educação Física, o professor licenciado será o responsável. Conforme se observa no quadro abaixo, em 2015, a AC Cultura do Movimento foi retirada da Matriz Curricular por meio da Resolução SE-6, e sua carga horária foi atribuída ao componente Língua Portuguesa.

Quadro 2 - Matriz curricular do ensino fundamental (anos iniciais).

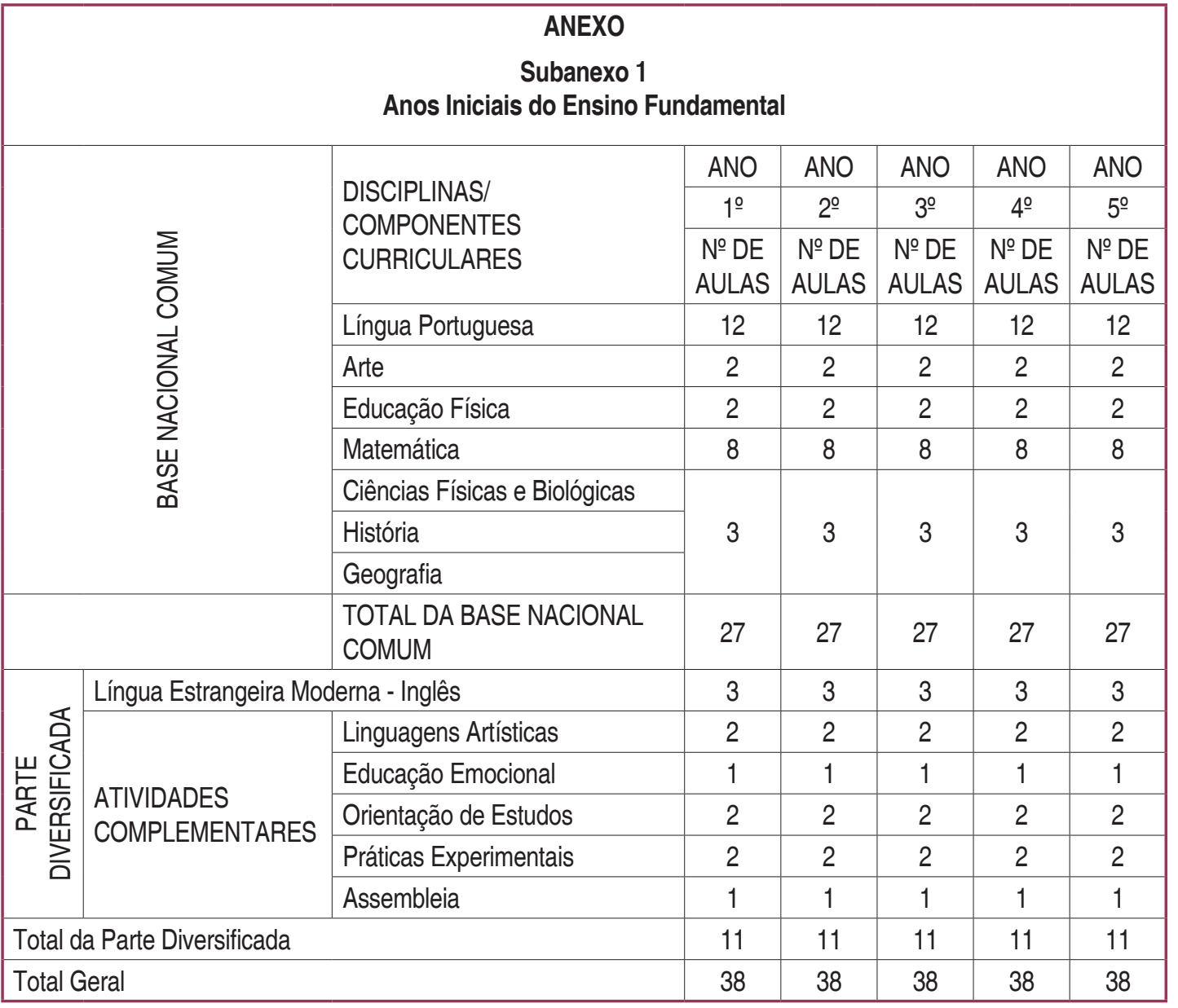

Fonte: Resolução SE 6, de 23/02/2015

Essa mudança, de acordo com Hess e Toledo (2016), evidencia a fragilidade da AC Cultura do Movimento, talvez devido à confusão com as aulas de Educação Física alocadas na BNC. Isso parece deflagrar a dificuldade da própria Secretaria da Educação em definir "o lugar" dessa atividade. Da forma como figurava na resolução anterior, a sobreposição com o componente curricular poderia ser interpretada simplesmente como "mais do mesmo".

Em relação aos papéis do professor de Educação Física, conforme consta no Guia (São Paulo, 2014a, p.9), "[...] os professores de Educação Física e Arte deverão também ministrar, em parceria, as aulas da atividade complementar de Linguagens Artísticas que englobará a cultura do movimento de forma interdisciplinar", contando com a colaboração do professor de Inglês. Para isso, tanto o licenciado em Educação Física como o licenciado em Arte deverão estudar e elaborar projetos ou situações de aprendizagem, contemplando ambas as atividades 
que potencializem as capacidades dos estudantes ao se movimentarem e interagirem no meio físico, social e cultural em que vivem, a partir de aquisições físico-artísticas (SÃO PAULO, 2014b).

Além disso, os professores de Arte e Educação Física, nas escolas de Ensino Integral dos anos iniciais, deverão:

[...] desenvolver atividades diversificadas no horário do almoço, para acompanhar os alunos. Sendo que nas escolas que optarem por 1 hora e meia de almoço por dia, serão atribuídas 10 aulas semanais, correspondendo a 2 aulas de acompanhamento por dia. E nas escolas que optarem por 1 hora de almoço por dia, serão atribuídas 5 aulas semanais, correspondendo a 1 aula de acompanhamento por dia. Obs.: 0 professor irá cumprir sua hora de almoço em outro horário (SÃO PAULO, 2014a, p.9).

Uma observação a ser feita é que, no horário de almoço, os alunos serão acompanhados, também nos primeiros 30 minutos, pelo Professor de Referência ${ }^{3}$ da sala, o professor de Inglês e o professor colaborativo para organização e garantia do almoço de sua turma.

Devido a essa responsabilidade para a composição da carga horária de trabalho dos professores de Educação Física e Arte, como mencionado acima, é possível apontar que não foram descritos nos documentos critérios justificáveis para que os professores de Arte e Educação Física ocupassem o tempo de almoço completo. Além disso, sua condição de "desenvolvedor" de atividades diversificadas parece soar muito mais com "desenvolvedor" de atividades "avulsas" de caráter recreativo, com o objetivo de ocupar o tempo livre dos alunos.

O Guia (SÃO PAULO, 2014a, p.13) explica que especialistas "deverão organizar atividades/aulas dirigidas para as crianças no horário de almoço, garantindo assim um momento de aprendizagem". Por um lado, temos esses professores com funções de auxiliares ou monitores e privados do próprio horário de almoço e, por outro, os alunos sem o direito a atividades livres para brincar como quiserem, descansar etc., numa visão funcionalista e utilitária de mundo, na qual nem o horário da alimentação pode deixar de ser útil, tendo os alunos que "aprender".

Identificamos então um retrocesso aos tempos ditatoriais, quando o Decreto 69.450 de 01/11/1971 determinava que a "Educação Física, desportiva e recreativa integrará, como atividade escolar regular, o currículo dos cursos de todos os graus de qualquer sistema de ensino" (BRASIL, 1971, p. 8826). Na visão de Castellani Filho (1988), o referido documento legal previa a Educação Física como uma atividade pautada no fazer pelo fazer voltada à educação do físico, sem reflexões, apenas um meio para aprimorar a força de trabalho.

Contudo, conforme analisado nos documentos, e ainda mais sequencialmente, o professor de Educação Física na escola de Ensino Integral deve exercer funções que extrapolam a própria formação, muito provavelmente em decorrência das conotações atribuídas ao componente ao longo de sua história: higienista, qualificação da força de trabalho, formação integral, esportivista, recreador etc.

Outro papel que o professor de Educação Física deve assumir na Escola de Ensino Integral é a participação nas aulas de Assembleias, conjuntamente com a equipe gestora, professores regentes e especialistas. As Assembleias se dão uma vez por semana na PD das 
AC da Matriz Curricular e buscam discutir a resolução de problemas no ambiente escolar de forma coletiva. Tendo como fonte inspiradora a proposição de John Dewey, "[...] no século XX, várias experiências pedagógicas enfatizaram a necessidade de dar voz às crianças, levando em conta suas opiniões, inspiradas nas ideias da educação nova" (SÃO PAULO, 2014b, p. 61).

Mesmo sendo notável e importante a participação do professor de Educação Física nessas aulas, uma vez que nelas são debatidos e decididos diferentes aspectos do cotidiano escolar, o fato sinaliza para uma lacuna existente na formação do licenciado em Educação Física. Tal como sinalizaram Neira e Nunes (2006), a ausência de experiências formativas calcadas nas questões pedagógicas acaba por gerar uma postura por vezes inadequada ou fragilizada deste profissional.

Outro papel que pode ser desenvolvido pelos professores de Educação Física, dependendo da Unidade Escolar, e de maneira complementar à sua jornada de 32 aulas semanais, seria o de ministrar, com os demais docentes, outras disciplinas da Matriz Curricular, de preferência nos denominados agrupamentos, que podem ser, segundo as orientações do Guia (SÃO PAULO, 2014a), organizados homogeneamente, tendo como objetivo fazer com que os alunos que tenham algum tipo de dificuldade avancem por meio de atividades e intervenções diferenciadas.

Embora isso pareça ser uma solução para a questão do preenchimento da carga horária docente de diferentes disciplinas ou perfis de especialistas, ressalta-se que mais uma vez o professor está se distanciando de sua função social, pois os alunos que enfrentam dificuldades de aprendizagem necessitam ainda mais do Professor Referência, cuja trajetória formativa se mostra mais adequada. Ainda que o professor de Educação Física, acompanhado por outro(s) docente(s), também possa aprender e ensinar a partir das suas especificidades neste processo, para tanto, são fundamentais muitos estudos, planejamentos, o conhecimento das dificuldades de cada aluno e do trabalho interdisciplinar.

Outro papel mencionado pelos documentos oficiais refere-se ao acompanhamento dos alunos no horário da saída da escola, como segue:

\footnotetext{
- Para completar as 32 aulas, esses professores [de Educação Física, Arte e Inglês] irão ministrá-las em parceria com outros docentes da unidade escolar nas diversas disciplinas da Matriz Curricular, preferencialmente em atividades que contarão com agrupamentos. Essas aulas poderão ser remanejadas de acordo com a necessidade da escola e com decisão coletiva da equipe escolar.

- 4 aulas que correspondem ao horário de intervalo e saída dos alunos. Nestes momentos, o professor [de Educação Física, Arte e Inglês] poderá acompanhá-los caso haja necessidade (SÃO PAULO, 2014a, p. 9-10, grifo nosso).
}

Mais uma vez, encontramos no documento a descrição de um papel do professor que não condiz com sua formação profissional, embora, como educador do contexto escolar, ele possa cumpri-lo. Mesmo assim, este e os demais papéis definidos pela equipe elaboradora dos documentos analisados e destacados acima abordam justificativas para que este ou aquele docente de determinada formação cumpra papéis atrelados muito mais à ordem burocrática, para completar a jornada de trabalho, ao invés de valorizarem questões atreladas à natureza da especificidade de cada disciplina e da interdisciplinaridade, por meio do fortalecimento dos momentos de estudos nas horas em que o professor não está lecionando. Sendo assim, o professor de Educação Física acaba tendo um papel mais de "tapa buracos" do que um 
intelectual, que pode refletir e atuar acerca dos desafios cotidianos para possíveis mudanças, escolares e sociais.

\section{CONSIDERAÇÕES FINAIS}

Identificamos que as mudanças previstas nos documentos para Educação Física na escola de Ensino Integral nos anos iniciais do ensino fundamental estão relacionadas a um trabalho mais integrado e interdisciplinar do professor de Educação Física e Arte. Contudo, a natureza das formações é distinta, destacando que professor de Educação Física na graduação acessa conhecimentos superficiais que perpassam as Ciências Biológicas e Humanas, enquanto o colega de Arte percorre outra trajetória.

Conforme os documentos propostos evidenciaram, nessas escolas o papel do professor de Educação Física vai além do ato de planejar e ministrar sua disciplina e de planejar a avaliação dos alunos, englobando também as tarefas de:

a) acompanhar os alunos no horário da saída;

b) acompanhar os alunos no horário de almoço;

c) participar das aulas de Assembleias;

d) participar dos agrupamentos.

Apesar dos alunos permanecerem cerca de 40 horas semanais na escola de Ensino Integral, a quantidade de aulas de Educação Física não foi ampliada, permanecendo reduzida a dois tempos semanais. 0 fato pode ser encarado como uma desvalorização dos conhecimentos disponibilizados pelo componente e como uma atribuição de um papel secundário ao profissional, que assumirá as funções de disciplinador, recreador e auxiliar para cuidar do portão e das refeições.

Esses aspectos distanciam o professor de suas responsabilidades, dificultando, inclusive, seu processo de formação contínua. Os estudantes e a sociedade acabam sendo prejudicados diante da carência de experiências no campo da cultura corporal, algo que poderia ser bastante estimulado, já que os alunos permanecem na escola cerca de nove horas por dia.

A respeito da disciplina Cultura do Movimento, que poderia trazer um diferencial e uma perspectiva de melhorias para a área, esta não vingou, até, talvez, pela falta de uma proposta mais esclarecedora, que especificasse do que a disciplina trataria - se é que seja possível diferenciá-la e fragmentá-la do componente curricular da Educação Física. Isso porque, como foi apontado no decorrer deste estudo, vários termos relacionados à "cultura" são utilizados na área, mas o uso como nome de uma disciplina foi algo inédito na história da Educação Física.

Assim, é possível concluir que a proposta de Ensino Integral consubstanciada nos documentos elaborados pela Secretaria da Educação do Estado de São Paulo precisa ser revista com a participação e envolvimento dos docentes dos anos iniciais, das equipes gestoras e, principalmente, da comunidade, para que o debate do cotidiano seja instalado e mudanças efetivamente positivas ocorram. 


\section{REFERÊNCIAS}

BARDIN, Laurence. Análise de conteúdo. São Paulo: Edições 70, 2011.

BRACHT, Valter. A constituição das teorias pedagógicas da Educação Física. Cadernos

Cedes [online], v. 19, n. 48, p. 69-88, ago. 1999. Disponível em: <http://www.scielo.br/scielo. php?pid=S010132621999000100005\&script=sci abstract\&tlng=pt>. Acesso em: 17 maio 2018.

BRACHT, Valter et al. Pesquisa em ação: educação física na escola. 3.ed. ljuí: Ed. Unijuí, 2007.

BRASIL. Decreto no 69.450, de 1 de novembro de 1971. Regulamenta 0 artigo 22 da Lei número 4.024, de 20 de dezembro de 1961, e alínea c do artigo 40 da Lei 5.540, de 28 de novembro de 1968 e dá outras providências. Diário Oficial da União, Brasília, DF, Seção 1, 3/11/1971, p. 8826. Disponível em:< http://www2.camara.leg.br/legin/fed/decret/1970-1979/decreto-69450-1-novembro1971-418208-publicacaooriginal-1-pe.html>. Acesso em: 17 maio 2018.

BRASIL. Lei oㅜ 12.796, de 4 de abril de 2013. Altera a Lei o 9.394, de 20 de dezembro de 1996, que estabelece as diretrizes e bases da educação nacional, para dispor sobre a formação dos profissionais da educação e dar outras providências. Diário Oficial da União, Brasília, DF, Seção 1, 5/4/2013, p. 1. Disponível em: <http://www2.camara.leg.br/legin/fed/lei/2013/lei-12796-4abril-2013-775628-publicacaooriginal-139375-pl.html>. Acesso em: 16 out. 2018.

BRASIL. Ministério da Educação. Secretaria de Educação Fundamental. Parâmetros Curriculares Nacionais primeiro e segundo ciclos do Ensino Fundamental: Educação Física. Brasília, DF, 1997. Disponível em: <http://portal.mec.gov.br/seb/arquivos/pdf/livro07.pdf>. Acesso em: 17 fev.2018.

BRASIL. Ministério da Educação. Secretaria de Educação Fundamental. Parâmetros Curriculares Nacionais Terceiro e Quarto Ciclos do Ensino Fundamental: Educação Física. Brasília, 1998. Disponível em: <http://portal.mec.gov.br/seb/arquivos/pdf/fisica.pdf>. Acesso em: 17 fev.2018.

BRASIL. Ministério da Educação e Desporto. Secretaria da Educação Média e Tecnológica. Parâmetros Curriculares Nacionais: Ensino Médio. Brasília, 2000. Disponível em: <http://portal. mec.gov.br/seb/arquivos/pdf/blegais.pdf> Acesso em: 17 fev.2018.

CASTELLANI FILHO, Lino. Educação física no Brasil: a história que não se conta. Campinas: Papirus, 1988.

GIL, Antônio Carlos. Como elaborar projetos de pesquisa. 4. ed. São Paulo: Atlas, 2002.

GRAMORELLI, Lilian Cristina. A cultura corporal nas Propostas Curriculares Estaduais de Educação Física: novas paisagens para um novo tempo. 2014. 188 folhas. Tese (Doutorado em Educação) - Faculdade de Educação, Universidade de São Paulo, São Paulo, 2014.

HESS, Cássia Maria; TOLEDO, Eliana. A atuação do professor de Educação Física nos anos iniciais do ensino fundamental: uma abordagem legislativa. Revista Brasileira de Ciência e Movimento, v. 24, n. 1, p. 167-178, 2016. Disponível em: <https://portalrevistas.ucb.br/index.php/RBCM/article/ view/5766/4272>. Acesso em: 18 abr. 2018.

LOPES, Alice Casimiro; MACEDO, Elizabeth. Teorias de Currículo. São Paulo: Cortez, 2011.

NEIRA, Marcos Garcia; NUNES, Mário Luiz Ferrari. Pedagogia da cultura corporal: crítica e alternativas. São Paulo: Phorte, 2006. 
NEIRA, Marcos Garcia; GRAMORELLI, Lilian C. Embates em torno do conceito de cultura corporal: gênese e transformações. Revista Pensar a prática, v. 20, n. 2, p. 321-332, 2017. Disponível em: <https://www.revistas.ufg.br/fef/article/view/38103>. Acesso em: 18 jul.2018.

NEIRA, Marcos Garcia. Educação Física Cultural: inspiração e prática pedagógica. Jundiaí: Paco, 2018.

SÃO PAULO (Estado). Secretaria de Educação. Proposta Curricular do Estado de São Paulo: Educação Física. São Paulo, 2010. Disponível em: <http://www.educacao.sp.gov.br/a2sitebox/ arquivos/documentos/237.pdf>. Acesso em: 18 maio 2018.

SÃO PAULO (Estado). Secretaria de Educação.Diretrizes do Programa Ensino Integral, Escola de Tempo Integral. Programa Ensino Integral. São Paulo, 2012. Disponível em: <http://www. educacao.sp.gov.br/a2sitebox/arquivos/documentos/342.pdf>. Acesso em: 18 maio 2018.

SÃO PAULO (Estado). Secretaria de Educação. Guia de Organização Curricular dos Tempos e Espaços do Programa Ensino Integral nos anos iniciais do Ensino Fundamental. São Paulo, 2014a.

SÃO PAULO (Estado). Secretaria de Educação. Modelo Pedagógico do Programa de Ensino Integral nos anos iniciais do Ensino Fundamental. São Paulo, 2014b. Disponível em: <https:// pt.scribd.com/document/366502984/Modelo-Pedagogico-Pei-Anos-Iniciais-Do-Ef>. Acesso em: 22 jan.2018.

SÃO PAULO (Estado). Resolução SE-52. Dispõe sobre a organização e o funcionamento das escolas estaduais do Programa Ensino Integral. São Paulo, 2014c. Disponível em: <http://siau.edunet. sp.gov.br/ltemLise/arquivos/52 14.HTM> . Acesso em: 23 mar.2017.

SÃO PAULO (Estado). Resolução SE no 6. Altera dispositivos da Resolução SE 52, de 2-102014, que dispõe sobre a organização e o funcionamento das escolas estaduais do Programa Ensino Integral São Paulo, 2015. Disponível em: <http://siau.edunet.sp.gov.br/ltemLise/arquivos/6 15. HTM?Time=26/08/2018\%2013:23:18>. Acesso em: 23 mar.2017.

SILVA, Tomaz Tadeu. Documentos de Identidade: uma introdução às teorias do currículo. Belo Horizonte: Autêntica, 2013.

SOARES, Carmen Lúcia et al. Metodologia do ensino da Educação Física. São Paulo: Cortez; 1992. 